\title{
Resistant hypertension: Definition, evaluation, and new therapeutic approaches to treatment
}

\author{
Maria Leonarda De Rosa* \\ Department of Translational Medical Sciences, University of Naples Federico II, Italy
}

\begin{abstract}
Resistant hypertension is defined as blood pressure above the patient's goal despite the use of 3 or more antihypertensive agents from different classes at optimal doses, one of which should ideally be a diuretic. Although the exact prevalence of resistant hypertension is currently unknown, indirect evidence from population studies and clinical trials suggests that it is a relatively common clinical problem. The prevalence of resistant hypertension is projected to increase, owing to the aging population and increasing trends in obesity, sleep apnea, and chronic kidney disease. Evaluation of patients with resistive hypertension should first confirm that they have true resistant hypertension by ruling out or correcting factors associated with pseudoresistance such as white coat hypertension, suboptimal blood pressure measurement technique, poor adherence to prescribed medication, suboptimal dosing of antihypertensive agents or inappropriate combinations, the white coat effect, and clinical inertia. Management includes lifestyle and dietary modification, elimination of medications contributing to resistance, and evaluation of potential secondary causes of hypertension. Education and reinforcement of life-style issues that affect BP, such as sodium restriction, reduction of alcohol intake, and weight loss if obese, are critical in treating resistant hypertension. Pharmacological treatment should be tailored to the patient's profile and focus on the causative pathway of resistance. Exclusion of preparations that contribute to true BP treatment resistance, such as nonsteroidal anti-inflammatory agents, cold preparations, and certain herbs, is also important. Lastly, BP control can only be achieved if an antihypertensive treatment regimen is used that focuses on the genesis of the hypertension. An example is volume overload, a common but unappreciated cause of treatment resistance. Use of the appropriate dose and type of diuretic provides a solution to overcome treatment resistance in this instance. Patients with uncontrolled hypertension despite receiving an optimal therapy are candidates for newer interventional therapies such as carotid baroreceptor stimulation and renal denervation.
\end{abstract}

\section{Introduction}

Hypertension is the most common chronic disease in developed societies, affecting $>25 \%$ of adults [1]. Meta-analyses have demonstrated a linear relationship between level of blood pressure (BP) and risk for cardiovascular events [2-4]. Suboptimal BP control is, consequently, the most common attributable risk for death worldwide, being responsible for $62 \%$ of cerebrovascular disease and $49 \%$ of ischemic heart disease as well as an estimated 7.1 million deaths a year [5]. In the U.S., both the net and age-adjusted prevalence ratios of hypertension continue to increase. Recent data suggest, however, a slight improvement in hypertension awareness, treatment, and control [6]. The rates of hypertension treatment and control in Europe are much lower than in the U.S. [7]. Several large hypertension outcome trials also demonstrate a failure to achieve BP goals in spite of protocol-defined treatment regimens. In these trials, $20 \%$ to $35 \%$ of participants could not achieve $\mathrm{BP}$ control despite receiving $>3$ antihypertensive medications [8-10]. This article provides the clinician with an overview of the patient characteristics associated with resistant hypertension, the diagnostic evaluation to assess the problem, and the treatment strategies for optimizing BP control. Patients whose blood pressure is controlled but require 4 or more medications to do so should also be considered resistant to treatment. However, the definition does not include newly diagnosed hypertensives. Resistant hypertension is not synonymous with uncontrolled hypertension. The latter includes both patients with inadequately treated blood pressure due to poor adherence or inadequate treatment, as well as those with true resistant hypertension $[11,12]$. The importance of resistant hypertension lies in the identification of patients who are at high risk of suffering complications from reversible causes of hypertension and patients who may benefit from a particular diagnostic or therapeutic approach [11]. The exact prevalence of resistant hypertension is unknown, in part because of its arbitrary definition. However, small studies estimate prevalence from $5 \%$ in general medical practice up to $50 \%$ in nephrology clinics [13]. In a prospective analysis of Framingham study data, a higher baseline systolic blood pressure along with older age, the presence of $\mathrm{LVH}$ and obesity (BMI $>30 \mathrm{~kg} / \mathrm{m}^{2}$ ] were the strongest predictors of lack of blood pressure control $[14,15]$. Results were similar in ALLHAT where the older, obese patients with higher baseline systolic blood pressure and LVH required 2 or more antihypertensive agents [16]. The strongest predictor however was serum creatinine over $1.5 \mathrm{mg} / \mathrm{dL}$. Other patient characteristics associated with resistant hypertension include excessive salt ingestion, diabetes, black race, and female gender. Both studies showed greater difficulty in controlling systolic blood pressure compared to diastolic. Up to $92 \%$ of patients achieved target diastolic blood pressure while only $60 \%-67 \%$ achieved systolic blood pressure goals [14-16]. It is likely that this condition will become increasingly common because of the aging population and a progressive increase in obesity and comorbidities such as diabetes. There are also a few studies implicating gene mutations. A Finnish study found that certain variants of the $\beta$ and $\gamma$ subunits of the epithelial sodium channel gene

Correspondence to: Maria Leonarda De Rosa, Department of Translational Medical Sciences, University of Naples Federico II, Italy, Email: mlderosa@ unina.it

Key words: Resistant hypertension, management, evaluation, treatment

Received: October 02, 2017; Accepted: October 20, 2017; Published: October 23, 2017 
$\mathrm{ENaC}$ were significantly more prevalent in patients with resistant hypertension [17]. Other studies associate the allele of the CYP3A $5{ }^{\star} 1$ enzyme with both higher blood pressure levels in normotensive people of black race, as well as with hypertension resistant to treatment $[18,19]$. This particular enzyme is involved in the metabolism of cortisol and corticosterone. These and other genes that may be identified in the future hold the potential for the development of novel therapeutic targets.

\section{Pseudoresistance evaluation}

The term "pseudo-resistance" refers to lack of BP control with appropriate treatment in a patient who does not have resistant hypertension. Several factors contribute to elevated BP readings and produce the perception of resistant hypertension [20-22] (Table 1). Such factors include the following: 1 . suboptimal BP measurement technique; 2 . the white-coat effect; and 3. poor adherence to prescribed therapy and other causes described in the following text [11,21]. A careful evaluation to exclude these factors before labeling someone as having resistant hypertension should be performed. The first step in evaluating a patient with uncontrolled blood pressure is to establish whether it is a case of true resistant hypertension or just pseudoresistance. The latter refers to a lack of blood pressure control despite receiving treatment without true resistance. This can be caused by easily reversible causes such as suboptimal blood pressure measurement technique, poor adherence to prescribed medication, suboptimal dosing of antihypertensive agents or inappropriate combinations, the white coat effect, and clinical inertia. It is important to exclude these causes before labeling a patient as having resistant hypertension. Poor blood pressure measurement technique is quite common, usually the result of not letting the patient rest before measurement and using a small cuff [23] Patients should always rest in a chair with their back supported for a minimum 5 minutes prior to measurement and the cuff's air bladder must encircle at least $80 \%$ of the arm circumference. The average of two readings taken a minute apart represents the patient's blood pressure. Approximately $40 \%$ of newly diagnosed patients will discontinue their antihypertensive medication the first year of treatment [24,25]. Eventually, less than $40 \%$ will continue taking their medication after 5 to 10 years [24-26]. The most common causes are poor patientphysician communication concerning blood pressure goals and the importance of achieving them, potential side effects, high cost of treatment, and complex regimens $[27,28]$. Adherence can be improved by choosing affordable agents with minimal side effects that are given once daily alone or in fixed dose combinations. Older patients with memory deficits or psychiatric illness can benefit from using pill boxes. Clinical inertia can be described as a physician's ignorance of treatment guidelines or reluctance to adhere to them due to lack of training or

Table 1. Causes of pseudo-resistant Hypertension.

Improper blood pressure measurement

Heavily calcified or arteriosclerotic arteries that are difficult to compress (in elderly persons)

White-coat effect

Poor patient adherence

Side effects of medication

Complicated dosing schedules

Poor relations between doctor and patient

Inadequate patient education

Memory or psychiatric problems

Costs of medication

Related to antihypertensive medication

Inadequate doses

Inappropriate combinations

Physician inertia (failure to change or increase dose regimens when not at goal) inexperience in antihypertensive medication, underestimation of cardiovascular risk, and overestimation of the treatment provided [2030]. This results in suboptimal dosing or inappropriate combinations of agents. A large part of this problem could be resolved if physicians familiarize themselves with one or two drugs in each class of antihypertensives. Proper training is imperative so that physicians realize the importance of treating to reach a goal blood pressure level of less than $140 / 90 \mathrm{mmHg}$ and knowing when to refer patients to a hypertension specialist. A white coat effect should be suspected in patients whose clinical blood pressure measurements are consistently and significantly higher than reliable out of office measurements. Other signs include repetitive symptoms of overtreatment such as orthostatic hypotension and persistent fatigue as well as absence of target organ damage including left ventricular hypertrophy, retinopathy, and chronic kidney disease $[31,32]$. These cases must be confirmed with 24 hour ambulatory blood pressure monitoring. One study found that 20 to $30 \%$ of a patient population believed to have resistant hypertension was actually well controlled when measured by 24 -hour ambulatory blood pressure monitoring [33]. Accurate home blood pressure values are the best guide for therapy. In elderly patients, especially diabetics, arterial stiffness may cause pseudoresistance because less compressible arteries cause falsely elevated blood pressure [34].

\section{Identification and reversal of pseudo-resistance causes}

Reasonable algorithms to identify people with pseudo-resistant hypertension have been proposed $[11,20]$. In general, these approaches adopt a 2-step approach: first, confirmation of true resistance (by simultaneous recognition and correction of factors related to pseudoresistance); and second, identification of the factors that contribute to treatment resistance in a given patient (Table 2). The first step to rule out resistant hypertension is confirmation of the diagnosis with reliable office BP readings; the observer should strictly follow the relevant BP measurement guidelines [23]. Particular attention should be paid to the patient's posture, environment, and triple BP readings with adequate intervals between. Additionally, use of appropriate cuffs and devices is mandatory. Adherence to the recommended BP measurement technique will uncover patients who do not meet the definition of resistant hypertension. Identification of patients who have the whitecoat effect is also important. Either having qualified nonphysician personnel (i.e., nurses) perform office measurements or using an automated device with the patient alone in the room is useful. Of greater importance, however, is the determination of BP levels under treatment with home or ambulatory measurements, again following relevant recommendations $[23,35]$. If $\mathrm{BP}$ remains elevated after this evaluation, patient adherence to therapy should be evaluated, as noted earlier.

\section{Concomitant conditions}

Obesity is associated with resistant hypertension. Obese patients have increased sympathetic activity, higher cardiac output, and a rise in peripheral vascular resistance due to reduced endothelium-dependent vasodilation. Plasma aldosterone and endothelin are also increased, while excessive surrounding adipose tissue results in increased intrarenal pressures and changes in renal architecture [36]. As the body mass index increases, progressively higher doses of antihypertensive drugs are required to control blood pressure [37]. Weight loss has been found to reduce both systolic and diastolic blood pressure [11,38]. Another common concomitant condition in hypertensive patients is diabetes. Insulin resistance increases sympathetic nervous activity, vascular smooth muscle cell proliferation, and sodium retention 
Table 2. Factors contributing to resistant Hypertension.

\section{Drug-induced}

Nonsteroidal anti-inflammatory drugs (including cyclo-oxygenase-2 inhibitors)

Sympathomimetics (decongestants, anorectics)

Cocaine, amphetamines, other illicit drugs

Oral contraceptive hormones

Adrenal steroid hormones

Erythropoietin

Cyclosporine and tacrolimus

Licorice (included in some chewing tobacco)

Over-the-counter dietary and herbal supplements (e.g., ginseng, yohimbine, ma huang, bitter orange)

Excess alcohol intake

Volume overload

Excess sodium intake

Volume retention from kidney disease

Inadequate diuretic therapy

Associated conditions

Obesity

Diabetes mellitus

Older age

Identifiable causes of hypertension

Renal parenchymal disease

Renovascular disease

Primary aldosteronism

Obstructive sleep apnea

Pheochromocytoma

Cushing's syndrome

Thyroid diseases

Aortic coarctation

Intracranial tumors

leading to elevated blood pressure resistant to treatment [11]. The common comorbidities of obesity, hypertension, and diabetes induce renal dysfunction, further hindering blood pressure treatment. Dietary factors include increased salt and alcohol consumption. Although small amounts of alcohol ( 2 drinks/day) have vasodilating effects and may lower blood pressure, consumption of more than $30 \mathrm{~mL}$ daily raises blood pressure and may increase cardiovascular risk. Older patients, patients of African origin, and patients with chronic kidney disease are particularly susceptible to salt intake [11]. Current guidelines recommend that dietary sodium for a hypertensive person should be under $100 \mathrm{mmol} /$ day ( $2.4 \mathrm{~g}$ sodium or $6 \mathrm{~g}$ sodium chloride) and even lower in salt sensitive patients [39]. Excessive salt intake can be assessed by measuring sodium excretion in a 24-hour urine collection. Several common medications can cause elevated blood pressure and hinder treatment. Perhaps the most common are nonsteroidal antiinflammatories including COX-2 inhibitors and aspirin, decongestants (phenylephrine and pseudoephedrine), stimulant agents used for weight loss, narcolepsy or attention deficit disorder, contraceptives, cyclosporine, and erythropoietin [11]. Corticosteroids increase blood pressure through fluid retention, particularly but not limited to those with increased mineralocorticoid activity. Licorice and herbal medication that contains stimulants such as ephedra can also cause hypertension.

\section{Assessment of secondary causes of hypertension}

Apart from the aforementioned variables, a number of biological or life-style factors can contribute to the development of resistant hypertension. Several classes of pharmacological agents can produce transient or persistent increases in BP [40] (Table 3). Nonsteroidal antiinflammatory drugs (NSAIDs) are a common cause of worsening BP control. They increase BP by an average of $5 \mathrm{~mm} \mathrm{Hg}$, in part because of inhibition of renal prostaglandin production decreases in renal blood flow, followed by sodium and fluid retention [41]. They also interfere with BP-lowering of all antihypertensive drug classes except calcium antagonists [42-44]. The effect of NSAIDs on BP is more pronounced in patients with reduced kidney function [11]. Selective cyclo-oxygenase-2 inhibitors have effects similar to those of NSAIDs on BP control [45]. Sympathomimetic agents (nasal decongestants, anorectic pills, cocaine, amphetamine-like stimulants), oral contraceptives, glucocorticoids, anabolic steroids, erythropoietin, and cyclosporine are also commonly used agents that can interfere with BP control. Black licorice, included in some oral tobacco products, and herbal supplements (e.g., ma huang and ginseng), also raise BP [11,20,22]. The effect of these agents varies; most people manifest little or no effect, but certain persons may experience severe BP elevations. Lastly, illicit drugs can be a major unappreciated cause of resistant hypertension. Agents such as steroids and cocaine are common causes of resistant hypertension. Although modest alcohol consumption does not generally increase BP, larger amounts (3 or more drinks/day) have a dose-related effect on BP, both in hypertensive and normotensive persons [39]. Alcohol intake in all hypertensive patients should belimited to no more than $1 \mathrm{oz}$ of ethanol a day in most men (the equivalent of 2 drinks) and $0.5 \mathrm{oz}$ of ethanol a day in women and lower-weight persons [39]. A key factor responsible for many cases of resistant hypertension is excess dietary salt intake leading to volume overload [22]. Data from small studies demonstrate that $90 \%$ of patients with resistant hypertension have expanded plasma volume [46]. Excessive dietary sodium intake is widespread in the U.S. and other developed countries, with processed foods being the most common source $[11,22]$. The majority of patients with resistant hypertension have higher salt intake than the general population, with an average dietary sodium intake exceeding $10 \mathrm{~g}$ /day [47]. The optimal way to assess sodium intake is to measure sodium excretion in a $24-\mathrm{h}$ urine collection. Dietary salt reduction to $<3 \mathrm{~g}$ /day is associated with modest BP reductions, which are larger in African-American and elderly patients [48]. Current guidelines suggest that dietary sodium for a hypertensive person should be $<100 \mathrm{mmol} /$ day $(2.4 \mathrm{~g}$ sodium or $6 \mathrm{~g}$ sodium chloride) [39]. This guidance is applicable to all patients with resistant hypertension, whereas for salt-sensitive patients, even lower amounts of sodium may be necessary. Perhaps the most common

Table 3. Step-by-step physician guide for evaluation and management of patients appearing to have resistant Hypertension.

A. Become familiar with and adhere to the most recent hypertension guidelines.

B. Identify and reverse "pseudo-resistance."

1. Perform proper measurements of BP in the office, following the relevant guidelines, to confirm the diagnosis of resistant hypertension.

2. Exclude the "white-coat effect" with the use of home or ambulatory BP measurements. 3. Evaluate patient's adherence to the treatment regimens; in case of poor adherence, determine the causes of it. Educate the patient on the risks of uncontrolled hypertension and the benefits of drug treatment and motivate the patient to work toward an appropriate BP goal.

4. Closely follow-up nonadherent patients to ensure their compliance.

C. Identify and reverse factors contributing to true resistance.

1. Specifically ask the patient about use of any pharmacological agents that may increase $\mathrm{BP}$; in case of identification of such a substance, discontinue or minimize its use.

2. Evaluate the amount of alcohol intake and counsel the patient on the benefits of ceasing alcohol consumption.

3. Perform a reliable evaluation of dietary salt intake and recommend sodium restriction to $<100 \mathrm{mmol}(2.4 \mathrm{~g})$ per day.

4. Assess the degree of obesity, abdominal obesity, and physical activity and recommend weight reduction and regular aerobic exercise (at least $30 \mathrm{~min} / \mathrm{day}$, most days of the week). 5. Evaluate the level of renal function with estimation of glomerular filtration rate and modify treatment accordingly.

6. Perform a thorough search for secondary hypertension; if an identifiable cause is present, treat accordingly or refer the patient to a hypertension center.

D. Treat aggressively with optimal doses of appropriate antihypertensive medications (including drug combinations) according to patient characteristics.

E. Refer the patient to a hypertension specialist if BP control is not achieved.

$\mathrm{BP}=$ blood pressure. 
unappreciated medical cause of resistant hypertension is the presence of renal parenchymal disease. Kidney disease is the most common secondary medical cause of hypertension. Failure to appreciate this relationship may lead to less than optimal choices of antihypertensive agents such as failure to use appropriately dosed or selected diuretics based on kidney function. This lack of diuretic use has been shown in referral practices to be the primary cause of resistant hypertension, with the use of these agents helping to achieve BP goals [44]. Obesity is also a very common feature of patients with resistant hypertension $[16,49]$. The mechanisms by which obesity contributes to BP elevation and interferes with BP control are complex and not fully understood. Insulin resistance and hyperinsulinemia, impaired sodium excretion, increased sympathetic nervous system activity, increases in aldosterone sensitivity related to visceral adiposity, and obstructive sleep apnea have all been implicated as potential causes [50-52]. Weight loss achieved with both an appropriate exercise program and a reduced calorie diet is associated with modest $\mathrm{BP}$ reductions in obese hypertensive patients $[11,20]$. These reductions are greater in patients already receiving antihypertensive therapy [53]. Increasing age, namely, $>65$ years old, is associated with a higher prevalence of resistant hypertension $[22,54]$. Increasing age is associated with a higher prevalence of arterial stiffening, which is not only responsible for falsely elevated systolic $\mathrm{BP}$ readings but also a major cause of true elevations [22,39]. Current guidelines for systolic BP goals of $<140 \mathrm{~mm} \mathrm{Hg}$ are more difficult to achieve in patients with isolated systolic hypertension [39] and are more difficult with increasing age because of the natural history of arteriosclerosis. Finally, in patients with resistant hypertension, the presence of secondary hypertension must be considered; although its prevalence is largely unknown, previous studies have shown that $\approx 5 \%$ to $10 \%$ of patients with resistant hypertension have an identifiable cause $[29,55]$. As already mentioned, renal parenchymal disease must be considered with the strict sense as the most common medical cause of secondary hypertension [20,22]. Renal arterial disease, primary aldosteronism, and obstructive sleep apnea are other common identifiable causes, whereas less common forms of secondary hypertension include pheochromocytoma, Cushing's syndrome, hyperparathyroidism and hypoparathyroidism, aortic coarctation, and intracranial tumors (Table 3). The possibility of an identifiable cause of hypertension increases with age: renal disease, sleep apnea, and possibly primary aldosteronism are more prevalent among older patients $[11,56]$. Patients with documented resistant hypertension should be evaluated for secondary hypertension if indicated by clinical and routine laboratory evaluation [39]. Description of the signs and symptoms, diagnostic procedures, and treatment of identifiable causes of hypertension is beyond the scope of this article [11].

\section{Pharmacological treatment}

Suboptimal dosing regimens or inappropriate antihypertensive drug combinations are the most common causes of resistant hypertension $[29,55]$. Recommendations on the modification and intensification of antihypertensive regimens for a given patient taking 3 or more drugs is based on pharmacological principles in the context of the underlying pathophysiology that portends hypertension, clinical experience, and available treatment guidelines. The present rationale for intervention in resistant hypertension (Figure 1) is to ensure that all possible mechanisms for BP elevation are blocked. As volume expansion seems the most frequent pathogenic finding in these patients $[46,57]$, an appropriate diuretic to decrease volume overload remains a cornerstone of therapy $[20,23,58]$. Studies suggest that changes in diuretic therapy (adding a diuretic, increasing the dose, or changing the diuretic class based on kidney function) will help $>60 \%$ of these patients achieve BP goals [20,46,55,57-59]. Thiazide diuretics are effective from doses of $12.5 \mathrm{mg} /$ day given that kidney function is normal; increases up to $50 \mathrm{mg}$ may provide additional BP reduction in some patients [20]. Of note, there are differences between thiazide and thiazide-type diuretics $[11,21,60]$. A recent trial comparing hydrochlorothiazide $50 \mathrm{mg}$ and chlorthalidone $25 \mathrm{mg}$ daily demonstrated that the latter provided greater ambulatory BP reduction, with the largest difference occurring overnight [61]. Additionally, a small study of patients with resistant hypertension demonstrated that switching from the same dose of hydrochlorothiazide to chlorthalidone resulted in an additional $8 \mathrm{~mm}$ $\mathrm{Hg}$ drop in systolic BP and increased the number of subjects at goal [62]. Unfortunately, chlorthalidone is not commonly available in fixeddose combinations; therefore, its use will require separate prescriptions. The most crucial part of diuretic therapy is to know when kidney function has deteriorated, so that one may select the proper class of diuretic. For thiazides, this deterioration is generally thought to have occurred when the estimated glomerular filtration rate (eGFR) falls to $<50 \mathrm{ml} / \mathrm{min} / 1.73 \mathrm{~m}^{2}$; chlorthalidone can still be effective to an eGFR of $\approx 40 \mathrm{ml} / \mathrm{min} / 1.73 \mathrm{~m}^{2}$ if hypoalbuminemia or hyperkalemia is not present. For patients with eGFR $<40 \mathrm{ml} / \mathrm{min} / 1.73 \mathrm{~m}^{2}$, a loop diuretic should be used $[11,20,23]$. Furosemide or bumetanide must be given twice daily, and possibly thrice daily in some cases, as they have short durations of action of 3 to $6 \mathrm{~h}$. Thus, once-daily use is associated with intermittent natriuresis and consequent reactive sodium retention mediated by increases in the RAS $[20,23,63]$. The loop diuretic torsemide has a longer duration of action and may be given once or twice daily [20]. Use of the other drug classes in patients with resistant hypertension should be based on the general principles of combination therapy, namely, inhibition of different pathogenic mechanisms, choice of drugs that will compensate for possible pathophysiological changes evoked by the first drug, and consideration of compelling indications [20,39]. Moreover, the Food and Drug Administration has recently approved 3 fixed-dose combination antihypertensive agents for use as first-line therapy [64]. These combinations all have an agent that blocks the RAS. Fixed-dose antihypertensive combinations are also very useful for patients with resistant hypertension, especially for those with adherence problems $[65,66]$. Ultimately, patient characteristics (age, probable pathogenic mechanisms involved, and concomitant diseases) will determine the best combination of agents needed to achieve BP goal. In general, most patients should be on a blocker of the RAS along with a calcium antagonist and an appropriately dosed diuretic. In this case, the physician must ensure that these agents are prescribed in full dosages, especially for patients with increased weight, and for appropriate time intervals. If BP remains above goal, the next step is to add a fourth agent; a vasodilating beta-blocker is a good choice if pulse rate is not too low. Peripheral alpha-blockers are well tolerated and can be used if the beta-blocker selected does not have alpha-blocking activity. For true resistant hypertension, there are also good data to support adding a complementary calcium antagonist to a regimen including a RAS blocker, diuretic, and calcium-channel blocker (CCB); for example, adding long-acting diltiazem to nifedipine XL. Such a combination of complementary CCBs results in additive BP reduction with a low side effect profile and makes pharmacological sense $[67,68]$. Combining an angiotensin-converting enzyme (ACE) inhibitor with an angiotensin receptor blocker (ARB) does not make sense as it was recently shown to be less effective in terms of $B P$ reduction than was adding a diuretic or a CCB to an ARB [69], was shown not to reduce cardiovascular or renal events to any greater extent than individual agents, and may confer increased risk of side effects [70,71]. In a 


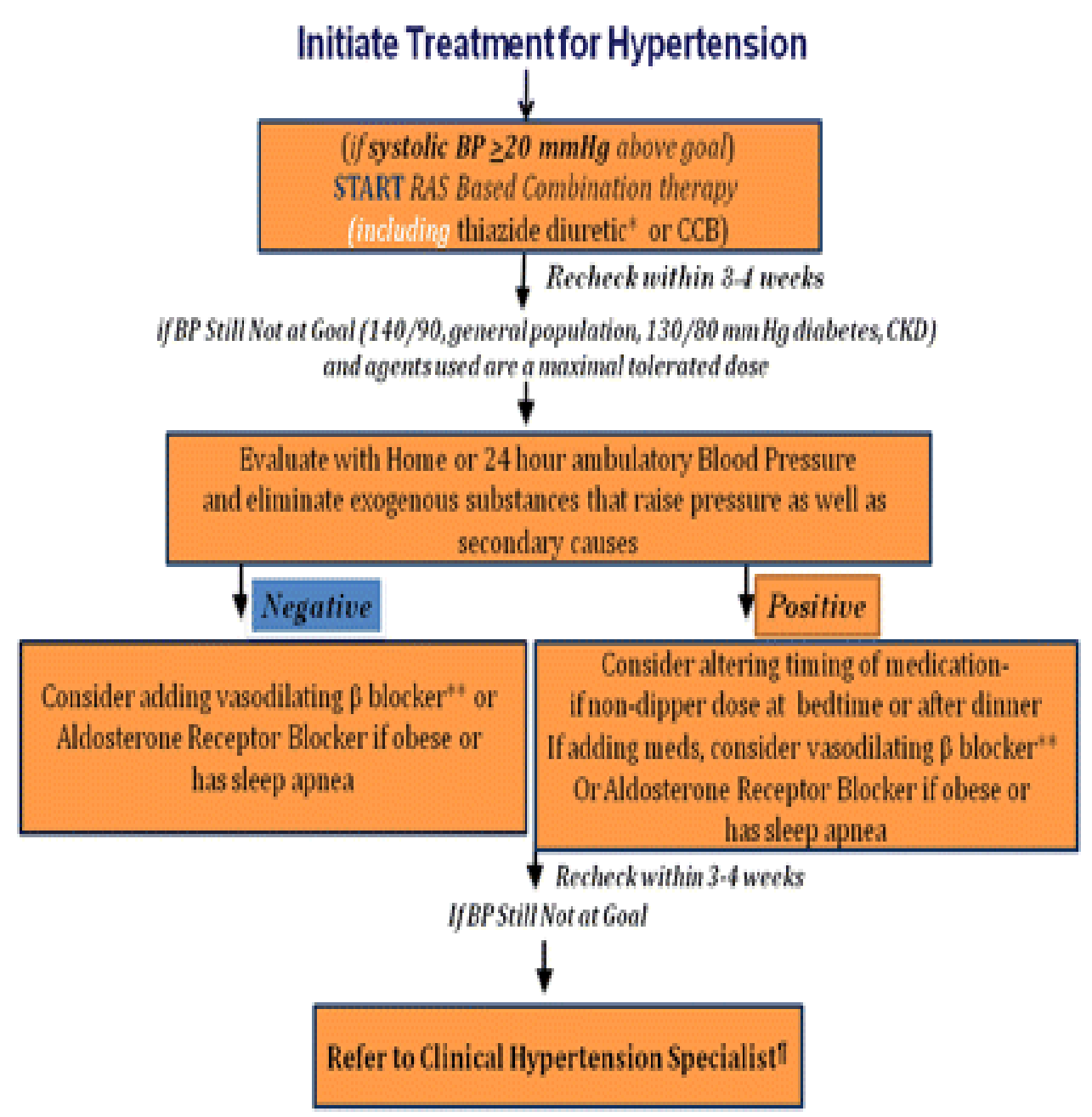

Figure 1. The present rationale for intervention in resistant hypertension.

separate trial, the combination of a renin inhibitor (aliskiren) with an ARB was also associated with a small additional BP drop [72]. Thus, dual RAS blockade is not recommended for patients with resistant hypertension. Aldosterone is also part of the RAS, and specific blockade of aldosterone should be considered in certain settings. Recent studies suggest that adding spironolactone or eplerenone to existing antihypertensive regimens for patients with resistant hypertension who are obese or have sleep apnea provides significant BP reduction $[11,73]$. For 76 patients with uncontrolled BP taking an average of 4 antihypertensive medications, the addition of spironolactone (12.5 to $25 \mathrm{mg}$ daily) resulted in an average $25 / 12 \mathrm{~mm} \mathrm{Hg}$ reduction after 6 months [74]. Reductions in BP were similar in patients with and without primary aldosteronism and were not predicted by baseline plasma or 24-h urinary aldosterone, plasma renin activity, or plasma aldosterone/renin ratio. These data were confirmed by a recent report of 1,411 participants in the Anglo-Scandinavian Cardiac Outcomes Trial-Blood Pressure Lowering Arm who were unselected for plasma aldosterone and renin activity [75] and who received spironolactone as a fourth-line antihypertensive agent for uncontrolled BP in addition to an average of 3 drugs. Use of spironolactone resulted in a BP drop of 21.9/9.5 $\mathrm{mm} \mathrm{Hg}$ that was unaffected by age, sex, smoking, and diabetic status. Breast tenderness with spironolactone is common at doses above $25 \mathrm{mg}$ /day but can be avoided with the use of the more selective mineralocorticoid receptor antagonist, epleronone [21]. Epleronone also has demonstrated BP-lowering efficacy as well as benefits on kidney disease progression [76]. Amiloride is another potassiumsparing diuretic associated with BP reductions in patients with resistant hypertension [77]. When physicians prescribe these agents, especially in combination with an ACE inhibitor or an ARB, they should monitor potassium levels closely if kidney function is not within the normal range, and educate the patient to avoid food and supplements rich in potassium, as hyperkalemia is a potentially dangerous side effect [21,78]. If BP control is still not achieved with full doses of a 4-drug combination, use of other agents such as centrally-acting alphaagonists (methyldopa and clonidine) or vasodilators (hydralazine or minoxidil) is needed. These agents are very effective for lowering BP, but have poor tolerability and lack of positive outcome data [39]. It must be noted, however, that if therapy has progressed to adding a fourth agent, referral to a clinical hypertension specialist is warranted [31]. Aliskiren, the only available direct renin inhibitor, is at least as effective as ARBs in reducing end target organ damage but has not been directly tested in resistant hypertension. The ALLAY trial showed that aliskiren monotherapy was as effective as losartan in reducing LVMI, although the combination of both did not achieve a statistically significant further LVMI regression [79]. The addition of aliskiren to losartan did however seem to have additional renoprotective effects in another study, reducing the mean urinary albumin creatinine ratio by $20 \%$ in patients with diabetic nephropathy [80]. The additional blood 
pressure reduction was marginal and therefore the role of direct rennin inhibitors in resistant hypertension remains undetermined. In any case, treatment should be tailored to the patient's profile, lifestyle, and comorbidities. Constructing a regimen that is acceptable to the patient, well tolerated and will maintain long-term compliance is important. Yet in some patients, optimal blood pressure control will not be achieved even with the most carefully designed regimen. In these cases, new device-based approaches for blood pressure control are being evaluated. One of these devices is the Rheos device (CVRx, Maple Grove, Minn) which stimulates the carotid baroreceptors for better blood pressure control by taking advantage of chronic electrical activation of the afferent limb of the carotid baroreflex. The device consists of a pulse generator and bilateral perivascular carotid sinus leads that are implanted under narcotic anesthesia. According to the findings from the Device-Based Therapy of Hypertension (DEBuTHT) study that were recently presented, after four years of treatment, Rheos reduced systolic blood pressure by an average of $53 \mathrm{mmHg}$ (193 $\mathrm{mmHg}$ versus $140 \mathrm{mmHg}$ ). Blood pressure was reduced significantly each year, with the largest decrease occurring in year four. Many of these patients were able to reach their blood pressure goal and reduce the number of medications that patients were taking to treat their hypertension from an average of 5 at baseline to 3.4 medications at 4 years. Baroreflex activation therapy also improved functional capacity and reduced left ventricular mass without any evidence of carotid injury or stenosis [81]. Another target for the interventional treatment of resistant hypertension is catheter-based renal nerve ablation. Renal sensory afferent nerve activity directly influences sympathetic outflow to the kidneys and other highly innervated organs involved in cardiovascular control, such as the heart and peripheral blood vessels, by modulating posterior hypothalamic activity [82,83]. All these components are stimulated in hypertension and contribute to blood pressure elevation. Renal sympathetic nerve ablation is achieved percutaneously via the lumen of the renal artery, using a catheter connected to a radiofrequency generator.

\section{Conclusion}

Although the number of patients who cannot achieve BP goals on a regimen of multiple medications is growing, the phenomenon of resistant hypertension is widely understudied, a fact that requires treatment recommendations be based on pathophysiological principles and clinical experience. Effective management of resistant hypertension requires, first, a careful examination for and exclusion of factors associated with pseudo-resistance, and second, identification and, when possible, modification of factors related to true BP elevations. After all of these are successfully managed, an aggressive treatment regimen designed to compensate for all mechanisms of BP elevation in a given patient, most importantly to control volume overload with proper use of diuretics, will help in moving toward effective BP control for the majority of patients.

\section{References}

1. Wolf-Maier K, Cooper RS, Banegas JR, Giampaoli S, Hense HW, et al. (2003) Hypertension prevalence and blood pressure levels in 6 European countries, Canada, and the United States. JAMA 289: 2363-2369. [Crossref]

2. Turnbull F, Neal B, Ninomiya T (2008) Effects of different regimens to lower blood pressure on major cardiovascular events in older and younger adults: meta-analysis of randomised trials. $B M J 336: 1121-1123$.

3. Lewington S, Clarke R, Qizilbash N, Peto R, Collins R (2002) Age-specific relevance of usual blood pressure to vascular mortality: a meta-analysis of individual data for one million adults in 61 prospective studies. Lancet 360: 1903-1913.

4. Adler AI, Stevens RJ, Manley SE, Bilous RW, Cull CA, Holman RR (2003) Development and progression of nephropathy in type 2 diabetes: the United Kingdom Prospective Diabetes Study (UKPDS 64) Kidney Int 63:225-232.
5. World Health Organization World Health Report 2002: Reducing Risks, Promoting Healthy LifeGeneva, Switzerland: World Health Organization; 2002.

6. Ong KL, Cheung BM, Man YB, Lau CP, Lam KS (2007) Prevalence, awareness, treatment, and control of hypertension among United States adults 1999-2004. Hypertension 49: 69-75. [Crossref]

7. Wolf-Maier K, Cooper RS, Kramer H (2004) Hypertension treatment and control in five European countries, Canada, and the United States. Hypertension 43: 10-17.

8. ALLHAT Officers and Coordinators for the ALLHAT Collaborative Research Group (2002) Major outcomes in high-risk hypertensive patients randomized to angiotensin-converting enzyme inhibitor or calcium channel blocker vs diuretic: The Antihypertensive and Lipid-Lowering Treatment to Prevent Heart Attack Trial (ALLHAT) JAMA 288: 2981-2997. [Crossref]

9. Dahlöf B, Devereux RB, Kjeldsen SE, Julius S, Beevers G, et al. (2002) Cardiovascular morbidity and mortality in the Losartan Intervention for Endpoint reduction in hypertension study (LIFE): a randomised trial against atenolol. Lancet 359: 995-1003. [Crossref]

10. Pepine CJ, Handberg EM, Cooper-DeHoff RM, et al. (2003) A calcium antagonist vs a non-calcium antagonist hypertension treatment strategy for patients with coronary artery disease. The International Verapamil-Trandolapril Study (INVEST): a randomized controlled trial. JAMA 290: 2805-2816.

11. Calhoun DA, Jones D, Textor S (2008) Resistant hypertension: diagnosis, evaluation, and treatment: a scientific statement from the American Heart Association Professional Education Committee of the Council for High Blood Pressure Research. Circulation 117(25): e510-e526.

12. Epstein M (2007) Resistant hypertension: prevalence and evolving concepts. Journal of Clinical Hypertension 9(1): 2-6.

13. Kaplan NM (2005) Resistant hypertension. J Hypertens 23: 1441-1444. [Crossref]

14. Lloyd-Jones DM, Evans JC, Larson MG, O’Donnell CJ, Roccella EJ, et al. (2000) Differential control of systolic and diastolic blood pressure factors associated with lack of blood pressure control in the community. Hypertension 36(4): 594-599.

15. Lloyd-Jones DM, Evans JC, Larson MG, Levy D (2002) Treatment and control of hypertension in the community: a prospective analysis. Hypertension 40: 640-646. [Crossref]

16. Cushman WC, Ford CE, Cutler J (2002) Success and predictors of blood pressure control in diverse North American settings: the antihypertensive and lipid-lowering treatment to prevent heart attact trial (ALLHAT) Journal of Clinical Hypertension 4(6): 393-404.

17. Hannila-Handelberg T, Kontula K, Tikkanen I (2005) Common variants of the beta and gamma subunits of the epithelial sodium channel and their relation to plasma renin and aldosterone levels in essential hypertension. BMC Medical Genetics 6: pp. 4.

18. Givens RC, Lin YS, Dowling AL, Thummel KE, Lamba JK, et al. (2003) CYP3A5 genotype predicts renal CYP3A activity and blood pressure in healthy adults. $J$ Appl Physiol (1985) 95: 1297-1300. [Crossref]

19. Ho H, Pinto A, Hall SD, Flockhart DA, Li L, et al. (2005) Association between the CYP3A5 genotype and blood pressure. Hypertension 45: 294-298. [Crossref]

20. Moser M, Setaro JF (2006) Clinical practice. Resistant or difficult-to-control hypertension. N Engl J Med 355: 385-392. [Crossref]

21. Pimenta E, Gaddam KK, Oparil S (2008) Mechanisms and treatment of resistant hypertension. J Clin Hypertens (Greenwich) 10: 239-244. [Crossref]

22. Sarafidis PA, Bakris GL (2008) State of hypertension management in the United States: confluence of risk factors and the prevalence of resistant hypertension. J Clin Hypertens (Greenwich) 10: 130-139.

23. Pickering TG, Hall JE, Appel LJ (2005) Recommendations for blood pressure measurement in humans and experimental animals - part 1: blood pressure measurement in humans - a statement for professionals from the Subcommittee of Professional and Public Education of the American Heart Association Council on high blood pressure research. Circulation 111(5): 697-716.

24. Caro JJ, Speckman JL, Salas M, Raggio G, Jackson JD (1999) Effect of initial drug choice on persistence with antihypertensive therapy: the importance of actual practice data. Canadian Medical Association Journal 160(1): 41-46.

25. Mazzaglia G, Mantovani LG, Sturkenboom MCJM (2005) Patterns of persistence with antihypertensive medications in newly diagnosed hypertensive patients in Italy: a retrospective cohort study in primary care. Journal of Hypertension 23(11): 2093-2100.

26. Van Wijk BL, Klungel OH, Heerdink ER, de Boer A (2005) Rate and determinants of 10-year persistence with antihypertensive drugs. J Hypertens 23: 2101-2107. [Crossref] 
27. Wildman RP, Gu D, Muntner P, Huang G, Chen J, et al. (2005) Alcohol intake and hypertension subtypes in Chinese men. J Hypertens 23: 737-743. [Crossref]

28. Henningsen NC, Ohlsson O, Mattiasson I, Trell E, Kristensson H, et al. (1980) Hypertension, levels of serum gamma glutamyl transpeptidase and degree of blood pressure control in middle-aged males. Acta Medica Scandinavica 207(4): 245-251.

29. Garg JP, Elliott WJ, Folker A, Izhar M, Black HR (2005) Resistant hypertension revisited: a comparison of two university-based cohorts. American Journal of Hypertension 18(5): 619-626.

30. Forman JP, Stampfer MJ, Curhan GC (2005) Non-narcotic analgesic dose and risk of incident hypertension in US women. Hypertension 46: 500-507. [Crossref]

31. Trewet CL, Ernst ME (2008) Resistant hypertension: identifying causes and optimizing treatment regimens. Southern Medical Journal 101(2): 166-173.

32. Vidt DG (2003) Pathogenesis and treatment of resistant hypertension. Minerva Med 94: 201-214. [Crossref]

33. Brown MA, Buddle ML, Martin A (2001) Is resistant hypertension really resistant? American Journal of Hypertension 14(12): 1263-1269.

34. Pickering TG (2007) Arterial stiffness as a cause of resistant hypertension? Journal of Clinical Hypertension 9(5): 390-395.

35. O'Brien E, Asmar R, Beilin L (2005) Practice guidelines of the European Society of Hypertension for clinic, ambulatory and self blood pressure measurement. $J$ Hypertens 23: 697-701.

36. Hall JE (2003) The kidney, hypertension, and obesity. Hypertension 41: 625-633. [Crossref]

37. Kroon B. European Society of Hypertension 20th Meeting. Abstract 01, Oral Session 9D.

38. Calhoun DA (2006) Resistant or difficult-to-treat hypertension. J Clin Hypertens (Greenwich) 8: 181-186. [Crossref]

39. Chobanian AV, Bakris GL, Black HR (2003) Seventh report of the Joint Nationa Committee on Prevention, Detection, Evaluation, and Treatment of High Blood Pressure. Hypertension 42(6):1206-1252.

40. Grossman E, Messerli FH (2008) Secondary hypertension: interfering substances. $J$ Clin Hypertens (Greenwich) 10: 556-566. [Crossref]

41. Johnson AG, Nguyen TV, Day RO (1994) Do nonsteroidal anti-inflammatory drugs affect blood pressure? A meta-analysis. Ann Intern Med 121: 289-300. [Crossref]

42. Conlin PR, Moore TJ, Swartz SL, Barr E, Gazdick L, et al. (2000) Effect of indomethacin on blood pressure lowering by captopril and losartan in hypertensive patients. Hypertension 36: 461-465. [Crossref]

43. Bakris GL, Kern SR (1989) Renal dysfunction resulting from NSAIDs. Am Fam Physician 40: 199-204. [Crossref]

44. Singer GM, Izhar M, Black HR (2002) Goal-oriented hypertension management: translating clinical trials to practice. Hypertension 40: 464-469.

45. Whelton A, White WB, Bello AE, Puma JA, Fort JG; SUCCESS-VII Investigators (2002) Effects of celecoxib and rofecoxib on blood pressure and edema in patients > or $=65$ years of age with systemic hypertension and osteoarthritis. Am J Cardiol 90: 959-963. [Crossref]

46. Graves JW, Bloomfield RL, Buckalew VM Jr (1989) Plasma volume in resistan hypertension: guide to pathophysiology and therapy. Am J Med Sci 298: 361-365. [Crossref]

47. Nishizaka MK, Pratt-Ubunama M, Zaman MA, Cofield S, Calhoun DA (2005) Validity of plasma aldosterone-to-renin activity ratio in African American and white subjects with resistant hypertension. Am J Hypertens 18: 805-812.

48. Vollmer WM, Sacks FM, Ard J, Appel LJ, Bray GA, et al. (2001) Effects of diet and sodium intake on blood pressure: subgroup analysis of the DASH-sodium trial. Ann Intern Med 135: 1019-1028. [Crossref]

49. Bramlage P, Pittrow D, Wittchen HU, Kirch W, Boehler S, et al. (2004) Hypertension in overweight and obese primary care patients is highly prevalent and poorly controlled. Am J Hypertens 17: 904-910. [Crossref]

50. Morris MJ (2008) Cardiovascular and metabolic effects of obesity. Clin Exp Pharmacol Physiol 35: 416-419. [Crossref]

51. Sarafidis PA (2008) Obesity, insulin resistance and kidney disease risk: insights into the relationship. Curr Opin Nephrol Hypertens 17: 450-456. [Crossref]
52. Wong C, Marwick TH (2007) Obesity cardiomyopathy: pathogenesis and pathophysiology. Nat Clin Pract Cardiovasc Med 4: 436-443. [Crossref]

53. Aucott L, Poobalan A, Smith WC, Avenell A, Jung R, et al. (2005) Effects of weight loss in overweight/obese individuals and long-term hypertension outcomes: a systematic review. Hypertension 45: 1035-1041.

54. Calhoun DA, Zaman MA, Nishizaka MK (2002) Resistant hypertension. Curr Hypertens Rep 4: 221-228. [Crossref]

55. Yakovlevitch M, Black HR (1991) Resistant hypertension in a tertiary care clinic. Arch Intern Med 151: 1786-1792. [Crossref]

56. Anderson GH Jr, Blakeman N, Streeten DH (1994) The effect of age on prevalence of secondary forms of hypertension in 4429 consecutively referred patients. J Hyperten 12: 609-615. [Crossref]

57. Taler SJ, Textor SC, Augustine JE (2002) Resistant hypertension: comparing hemodynamic management to specialist care. Hypertension 39: 982-988

58. Jamerson K, Bakris GL, Dahlof B (2007) Exceptional early blood pressure control rates: the ACCOMPLISH trial. Blood Press 16: 80-86.

59. Black HR, Elliott WJ, Grandits G (2003) Principal results of the Controlled Onse Verapamil Investigation of Cardiovascular End Points (CONVINCE) trial. JAMA 289: 2073-2082.

60. Handler J (2007) Maximizing diuretic therapy in resistant hypertension. $J$ Clin Hypertens (Greenwich) 9: 802-806. [Crossref]

61. Ernst ME, Carter BL, Goerdt CJ (2006) Comparative antihypertensive effects of hydrochlorothiazide and chlorthalidone on ambulatory and office blood pressure. Hypertension 47: 352-358

62. Khosla N, Chua DY, Elliott WJ, Bakris GL (2005) Are chlorthalidone and hydrochlorothiazide equivalent blood-pressure-lowering medications? $J$ Clin Hypertens (Greenwich) 7: 354-356.

63. Sarafidis PA (2007) Proteinuria: natural course, prognostic implications and therapeutic considerations. Minerva Med 98: 693-711.

64. Medical News Today (2007) FDA approves first combination therapy for initial use in patients with moderate to severe hypertension.

65. Khanna A, Lefkowitz L, White WB (2008) Evaluation of recent fixed-dose combination therapies in the management of hypertension. Curr Opin Nephrol Hypertens 17: 477 483. [Crossref]

66. Dickson M, Plauschinat CA (2008) Racial differences in medication compliance and healthcare utilization among hypertensive Medicaid recipients: fixed-dose vs freecombination treatment. Ethn Dis 18: 204-209.

67. Saseen JJ, Carter BL, Brown TE, Elliott WJ, Black HR (1996) Comparison of nifedipine alone and with diltiazem or verapamil in hypertension. Hypertension 28: 109-114. [Crossref]

68. Gashti CN, Bakris GL (2004) The role of calcium antagonists in chronic kidney disease. Curr Opin Nephrol Hypertens 13: 155-161. [Crossref]

69. Stergiou GS, Makris T, Papavasiliou M, Efstathiou S, Manolis A (2005) Comparison of antihypertensive effects of an angiotensin-converting enzyme inhibitor, a calcium antagonist and a diuretic in patients with hypertension not controlled by angiotensin receptor blocker monotherapy. J Hypertens 23: 883-889.

70. Yusuf S, Teo KK, Pogue J (2008) Telmisartan, ramipril, or both in patients at high risk for vascular events. $N$ Engl J Med 358:1547-1559.

71. Mann JF, Schmieder R, McQueen M (2008) Renal outcomes with telmisartan, ramipril, or both in people at high vascular risk: results from a multicenter, randomised, doubleblind, controlled trial. Lancet 372: 547-553.

72. Oparil S, Yarows SA, Patel S, Fang H, Zhang J, et al. (2007) Efficacy and safety of combined use of aliskiren and valsartan in patients with hypertension: a randomised, double-blind trial. Lancet 370: 221-229. [Crossref]

73. Pratt-Ubunama MN, Nishizaka MK, Boedefeld RL, Cofield SS, Harding SM. et al. (2007) Plasma aldosterone is related to severity of obstructive sleep apnea in subjects with resistant hypertension. Chest 131:453-459.

74. Nishizaka MK, Zaman MA, Calhoun DA (2003) Efficacy of low-dose spironolactone in subjects with resistant hypertension. Am J Hypertens 16: 925-930. [Crossref]

75. Chapman N, Dobson J, Wilson S, Dahlöf B, Sever PS, et al. (2007) Effect of spironolactone on blood pressure in subjects with resistant hypertension. Hypertension 49: 839-845. [Crossref] 
76. Pitt B, Reichek N, Willenbrock R (2003) Effects of eplerenone, enalapril, and eplerenone/enalapril in patients with essential hypertension and left ventricular hypertrophy: the 4E-left ventricular hypertrophy study. Circulation 108:1831-1838.

77. Eide IK, Torjesen PA, Drolsum A, Babovic A, Lilledahl NP (2004) Low-renin status in therapy-resistant hypertension: a clue to efficient treatment. J Hypertens 22: 2217 2226. [Crossref]

78. Calhoun DA (2006) Resistant or difficult-to-treat hypertension. J Clin Hypertens (Greenwich) 8: 181-186. [Crossref]

79. Solomon SD, Appelbaum E, Manning WJ, et al. Effect of the direct renin inhibitor aliskiren, the angiotensin receptor blocker losartan, or both on left ventricular mass in patients with hypertension and left ventricular hypertrophy. Circulation. 2009;119(4):530-537.
80. Parving HH, Persson F, Lewis JB, Lewis EJ, Hollenberg NK; AVOID Study Investigators (2008) Aliskiren combined with losartan in type 2 diabetes and nephropathy. N Engl J Med 358: 2433-2446. [Crossref]

81. Sanchez LA, Illig K, Levy M, et al. Implantable carotid sinus stimulator for the treatment of resistant hypertension: local effects on carotid artery morphology. Annals of Vascular Surgery. 2010;24(2):178-184.

82. Campese VM, Kogosov E. Renal afferent denervation prevents hypertension in rats with chronic renal failure. Hypertension. 1995;25 (4, part 2):878-882

83. Campese VM, Kogosov E, Koss M. Renal afferent denervation prevents the progression of renal disease in the renal ablation model of chronic renal failure in the rat. American Journal of Kidney Diseases. 1995;26(5):861-865.

Copyright: $@ 2017$ De Rosa ML. This is an open-access article distributed under the terms of the Creative Commons Attribution License, which permits unrestricted use, distribution, and reproduction in any medium, provided the original author and source are credited. 